\title{
GIS Augmented Automatic Train Monitoring
}

\author{
Mohd Shoab \\ Department of Civil Engineering \\ IIT Roorkee \\ India
}

\author{
Kamal Jain \\ Department of Civil Engineering \\ IIT Roorkee \\ India
}

\author{
M. Shashi \\ Department of Civil Engineering \\ NIT Warangal \\ India
}

\begin{abstract}
Now a days managing train movement between stations in railways has become staggering task which involve human efforts like data transfer through phone. It is needed to be continuously monitor the trains approaching from neighboring stations, for safe train movement due to high density of trains on a track. Conventionally, station master monitor approaching /departing trains by using Route Relay Interlocking (RRI) system which can monitor trains between station blocks. In this paper a GIS augmented automatic train monitoring (GAATM) system is proposed for station master to monitor approaching/departing trains to/from station. If station master has interest in a specific train, He/she can search and monitor that train in real time. The proposed system is developed in $\mathrm{C \#}$ and java script using Microsoft Visual Studio 2010.
\end{abstract}

\section{Keywords}

GAATM, Train Monitoring, GIS, RRI, C\#, Java Script.

\section{INTRODUCTION}

The development of computer network is not only for the information sharing but also for monitoring objects remotely in real time [9]. Wireless network is playing a major role in monitoring objects in real time, with the help of GSM/GPRS network, it is easy to track objects in real time. Wireless based train monitoring can perform the high density train control due to its high amount of information transmission about train location, and it has the virtue to reduce costs for equipment investment and maintenance costs [5].

Conventionally station master monitor approaching/departing trains using RRI system. It is a big colorful display used to ensure that no two trains end up on the same track at the same time [2]. This system has the limitation of its proximity. Station master can track trains between station block only not beyond of its proximity. In RRI, an entire route through the station can be selected and all associated points and signals along the route can be set at once by pressing two buttons for receiving or dispatching trains. Figure 1 shows the conventional RRI.

The developed system is a new type of monitoring system for railway, which involves the digitization of the railway infrastructure, mobile equipment, Geographical Information System (GIS), Global Navigation Satellite System (GNSS), wireless network (e.g. GSM/GPRS), information integration etc. [5] to provide facility of monitor trains in real time to station master for better decision making. In this system, GIS is used to represent the spatial information of railway infrastructure.

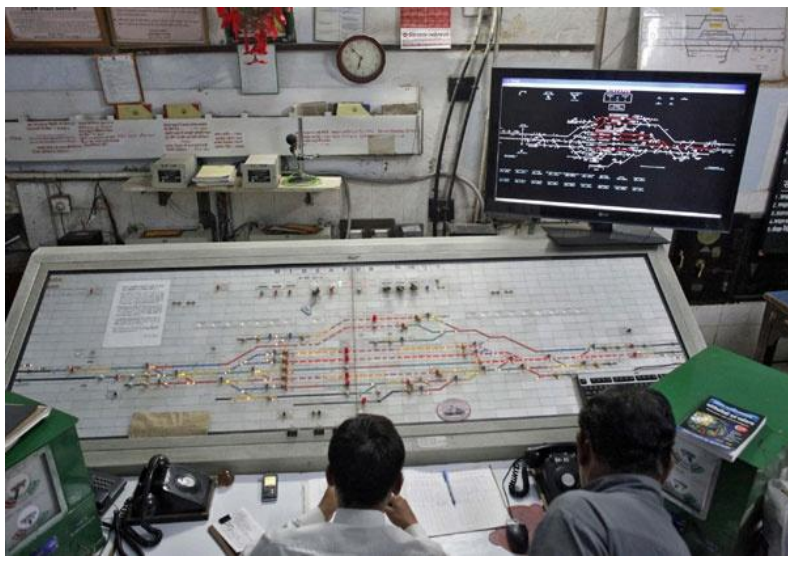

Fig 1: Route Relay Interlocking System (Source: How does the Inside of Control Room of Indian Railways Look Like.)

\subsection{Integration of GIS in Railway}

GIS integrates software, hardware and data for capturing, managing, analyzing and displaying all forms of geographically referenced information. GIS allow viewing, understanding, questioning, interpreting and visualizing data in many ways that reveal relationship, pattern and trends in the form of maps, globes, reports and charts [7].

In the railway industry geographic analysis is key that use to make better decisions. Understanding the issues such as monitoring rail systems, finding the best way to deliver goods and services, maintaining transportation infrastructure or tracking fleet vehicles from a geographical perspective is crucial to deploy or spend resources wisely. Hence railway transport finds great utility in using GIS to manage the information related to rail operations, maintenance, asset management, and decision support systems [3].

The Qinghai-Tibet Railway Bureau and the State Key Laboratory of Rail Traffic Control and Safety at Beijing Jiaotong University, design and develop a control center for Qinghai-Tibet Railway from Xining, Qinghai Province to Lhasa. The Monitoring System of Railway Operation and Safety for the Tibetan Line, displays maps which include 3D versions also, to track the train's location, check the real-time weather conditions along the route, and monitor the status of conditions inside and outside the cars such as the temperature inside passenger cars. A Global System for Mobile Communications for Railway (GSM-R) is used to solve highaltitude communication and data transmission challenges, which was provided by Nortel Network and Beijing Xidian. Figure 4 illustrate the GIS based Qinghai-Tibet Railway Bureau comprehensive monitoring system [1]. 
In the control center different types of real time information like train data (e.g. speed, location, passengers and staff), passenger car conditions (e.g. balance, temperature), and the electrical system (e.g. voltage, current) are merged together and displays it on digital maps. Users are able to browse maps, query and display infrastructure features by location, retrieve geographic data, photographs, videos and manage or search for metadata [1].

\section{ARCHITECTURE}

System architecture is the key element of any application. The system architecture defines how the modules of the application interact with each other, and what functionality each module is responsible for performing. The proposed system mainly follow the client server architecture in which the monitoring station is connected to a central server via wireless or wired network which contains the location information of trains. The GAATM system is the part of the intelligent train navigation and control system. GIS is used to represent the geographically related information in the proposed system. Figure 2 shows the architecture of the proposed system.

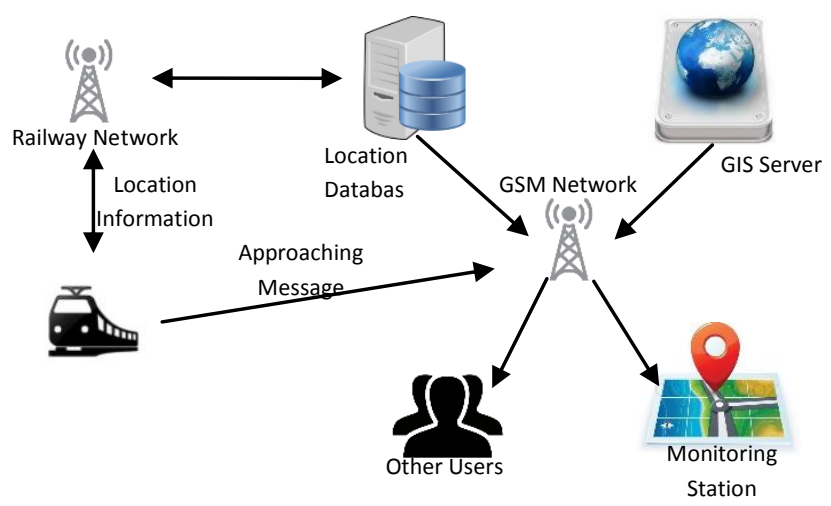

Fig 2: Architecture of Train Monitoring System.

This system monitors trains within its proximity or station proximity. The proximity of the station is neighboring stations (left and right stations). When a train leaves a station the onboard device of train send message to the next station, the monitoring system receive the message and automatically start monitoring the approaching train and generate alerts for the station master at the next station. This system is a GIS enabled monitoring system.

\section{DESIGN AND DEVELOPMENT}

In the world of applications which follow client-server architecture, the applications are built in distributed environment. A distributed application consumes the resources of multiple machines or at least multiple process spaces, by splitting the application functionality into more manageable groups of tasks that can be deployed in a wide variety of configurations. Dividing up an application in this routine results in the creation of a series of application layers or tiers, each of which is responsible for an individual, or atomic element of the applications processing.
Tiered applications can be characterized by the number of layers that information will pass through. Each layer generally runs on different systems, or in a different process space on the same system, than the other layers [8][4].

The GAATM system is designed and developed in visual studio 2010 with .net framework, c\# and uses three tier architecture. The GIS is used to integrate spatial information related to train and maps together. Java script is used for integration Google maps with the application. This system is the integration of windows and web application. A web browser is used to get the Google maps in the application. The proposed application can continuously monitor trains under its area of interest and generate notifications for station master. When a train approaches or leaves a station, this system generate notifications for station master and show train position on map. The developed system provide real time train monitoring with the latency of 20 seconds and accuracy of 510 meters which is depends on remote GNSS device which is used in on-board system.

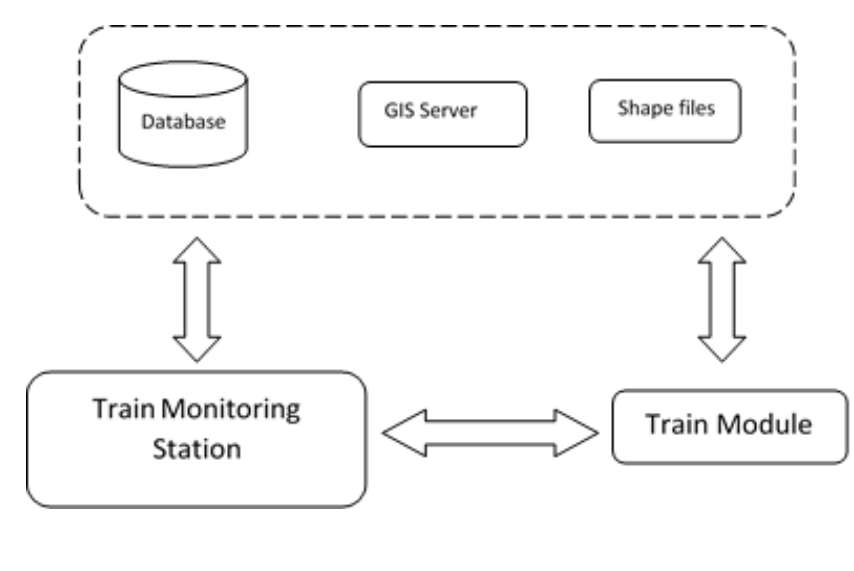

Fig 3: Data flow between monitoring station, server and trains.

\section{SIMULATION AND RESULT}

Before the actual test, a simulation process was done using GAATM system. Roorkee railway station was selected for the simulation and data for simulation was prepared by the various sources. Iqbalpur (left station) and Dhandhera (right station) is the two neighboring station of Roorkee railway station. Shape file is imported on Google map to visualize the proximity of the station.

When the station master wants to track real time location of a particular train, he/she should search the train number in database and select the train number, another window popped up and shows the real time train location of the selected train. Figure 5 illustrating the real time location of selected train. In other scenario when the train number 14318 leave the Iqbalpur Railway station, the onboard train device sends a message to the Roorkee Railway station master, the train monitoring system automatically starts the monitoring train and generates a warning of train approaching for station master. Figure 6 is illustrating the automatic monitoring feature of the developed application. 


\section{CONCLUSION}

This paper proposed GIS augmented automatic train monitoring system for the station master. Proposed system fulfils the requirement of automatic train monitoring for better decision making. The result of simulation process shows that the proposed system works as per expectation and useful for station master. Proposed system is the enhancement in conventional RRI based train monitoring and control system. This system reduces the human intervention in monitoring trains.

\section{REFERENCES}

[1] Enterprise GIS Helps Safeguard the Qinghai-Tibet Railway. By "http://www.esri.com/news/arcwatch/0308/ feature.html". Accessed on 7th January, 2014.

[2] How does the Inside of Control Room of Indian Railways Look Like. By "http://www.quora.com/India/How-does-the-inside-ofcontrol-room-of-Indian-railways-look-like-How-do-theguys-in-the-control-room-communicate-with-the-enginedriver". Accessed on 5th January, 2014.

[3] Guler, H. and Jovanovic, S. 2004. "The Application of Modern GIS Technology in the Development of Railway Asset Management System", IEEE International Conference on System, Man and Cybernetics, vol. 5, pp. 4153-4158, doi: 10.1109/ICSMC.2004.1401182.
[4] Shoab, M., Jain, K. and Shashi, M. 2013. "GNSS Based Real time Train Monitoring: A Web Approach", International Journal of Computer Applications, Vol. 73 No. 14 , pp. $34-41$.

[5] Oh, S., Yoon, Y., Kim, K. and Kim, Y. 2012. "Design of train integrity monitoring system for radio based train control system," 12th International Conference on Control, Automation and Systems (ICCAS 2012), pp. $1237-1240$

[6] Wang, Y., Li, P., Guo, G., Ma, X., Lu, W., Wu, Y. and Shi, Y. 2012. "Digital Railway System", Institute of Computing Technologies, China Academy of Railway Sciences, Beijing, China.

[7] What is GIS? By "http://www.esri.com/what-isgis/overview\#toverview panel". Accessed on 7th January, 2014.

[8] What is Web Development? By "http://www.yourmaindomain.com/web-articles/what-isweb-development.asp". Accessed on 9th May, 2013.

[9] Zhao, D., Zhang, S., and Gao, W. 1993. "The implementation of automatic monitoring network system for trains", Region 10 Conference on Computer, Communication, Control and Power Engineering.1993 IEEE TENCON '93. Proceedings, vol. 4, pp. 72-75, doi: 10.1109/TENCON.1993.320437.

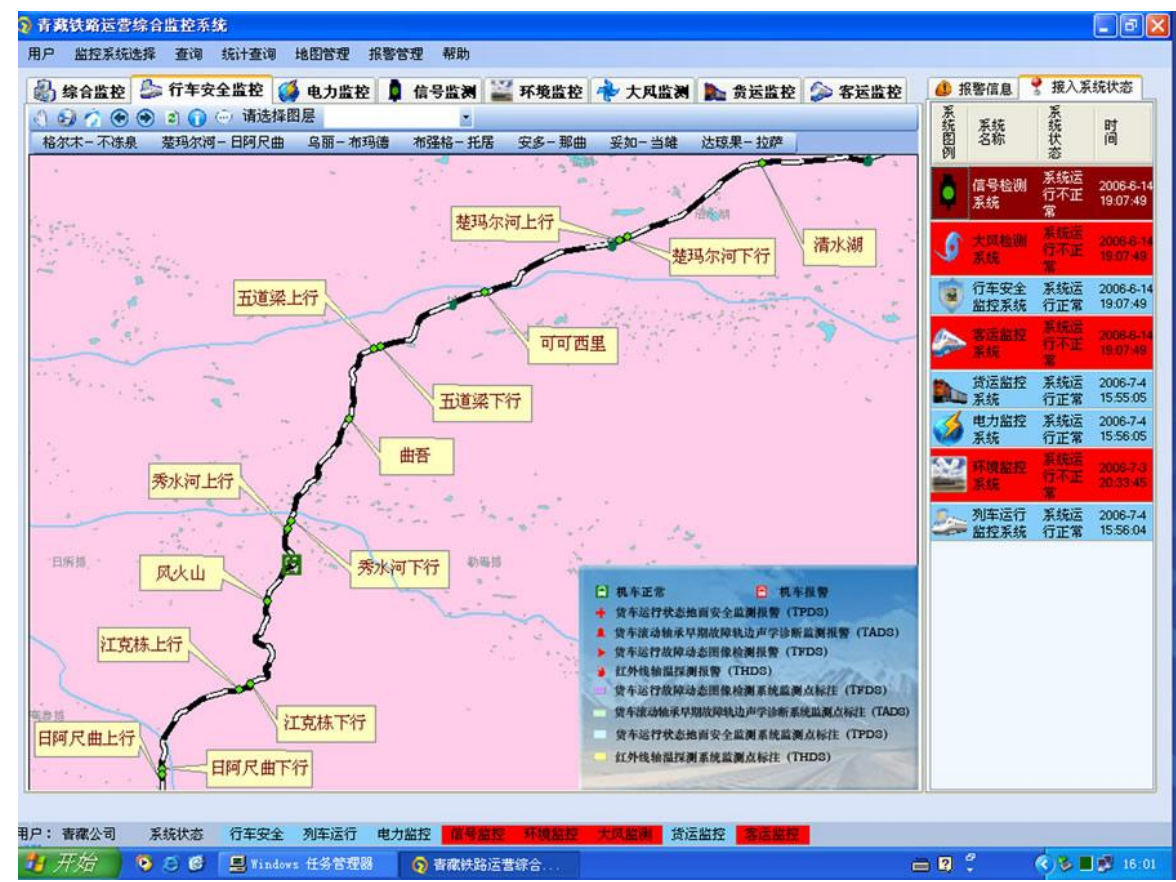

Fig 4: GIS based Qinghai-Tibet Railway Bureau comprehensive monitoring system (Source: Enterprise GIS Helps Safeguard the Qinghai-Tibet Railway) 


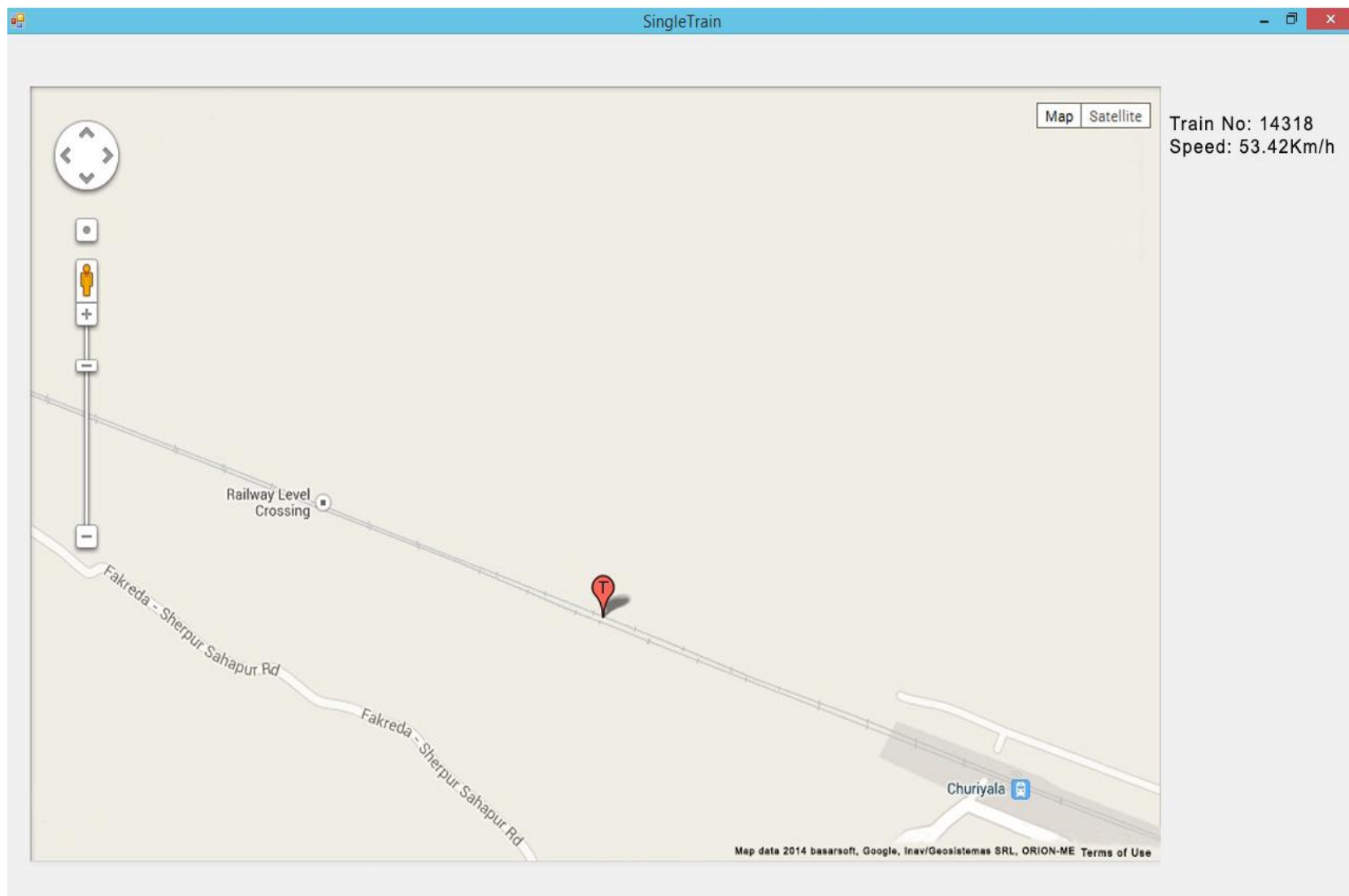

Fig 5: Selected Train Monitoring Window

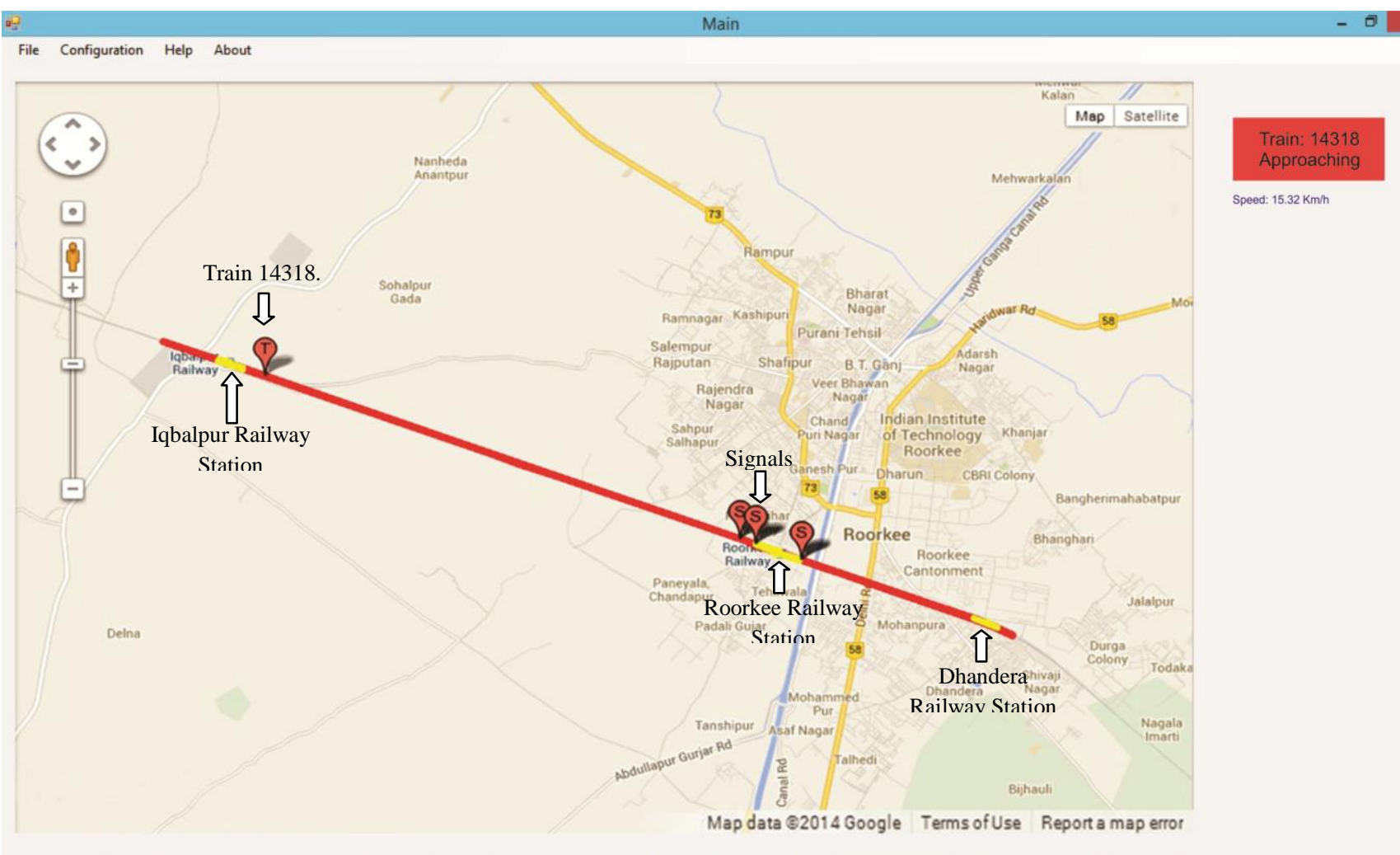

Fig 6: Automatic Train Monitoring with Warning 